\title{
General professional training: consultant supervision of trainees
}

\author{
John R. Robertson \& Anne Dean
}

'Educational supervisor' is the term now used by the General Medical Council for a consultant who has junior doctors working with him/her, whether employed by the National Health Service or a university. This paper represents our views of the role of the educational supervisor, rather than official College policy.

In the College statement on the criteria which have to be met for a training post to be educationally approved (available from Jane Hinton, Royal College of Psychiatrists Postgraduate Educational Services), specific emphasis is given to the direction, purpose and content of supervision. Many consultants are already hard-pressed and would welcome guidance about these developing educational commitments. It could also assist in any negotiations with general management.

The apprenticeship model is generally regarded as the one best suited to teaching medicine, and this remains the educational base for postgraduate teaching in psychiatry. "Apprenticeship will not need to be reinvented, but simply reorganised and valued ..." (Buckley, 1995). The apprenticeship model requires trainees to spend significant periods of time with their consultant, while the latter is actively engaged in clinical work. Most importantly, this includes ward rounds, out-patient clinics and community visits. For clinical teaching purposes ward rounds may be of less help than is generally believed. Even though clinical skills are paramount, multi-disciplinary meetings call on group skills and management skills as well. These are important, but leave less time for clinical teaching. Nevertheless, exposure of trainees to Care Programme Approach meetings, risk assessments, Section 117 meetings and multidisciplinary discussions is of great importance.
Some consultants do not see patients on ward rounds, preferring to conduct the patients' interviews separately without a large, intimidating group of professionals. If this is so, then the temptation for the trainee to depart on alternative urgent business at the end of the formal ward round must be guarded against. Other consultants feel that ward rounds should include the patient, especially in general adult psychiatry. They argue that trainees need to recognise the importance of seeing patients together with other members of the multi-disciplinary team. This avoids 'splitting', and allows the participants to see each other's perspectives on patient management. This can have considerable educational value.

Despite occasional competing demands from medical students, the out-patient clinic is probably the ideal setting for clinical skills to be taught and supervised, especially in the presentation of new cases. However, the educational supervisor must see their trainee at work in order to shape their interview skills, and guide them in their presentational skills.

Another useful training exercise is to provide a 10-minute slot for a case presentation similar to that expected for the MRCPsych Part I examination. Most centres are now equipped with video cameras and can organise practice sessions on a regular basis. The abbreviated six-to seven-minute slot for the Part II examination represents a good summary to a general practitioner or a colleague. Hence, the presentation of a treatment plan for case management under Part II examination conditions can be a very valuable exercise. Interview skills training does not necessarily require supervision of the entire history-taking, although that may be done at the very beginning. A 10 -minute sample

John Robertson (Horton Hospital, Long Grove Road, Epsom, Surrey KT19 8PZ) is a Sub-Dean of the College and late Convenor for the Central Approval Panel. He is Deputy Regional Adviser for CPD in North Thames and Divisional Representative on the College Tutors' Committee. Anne Dean is Head of Postgraduate Educational Services at the Royal College of Psychiatrists. 
of interviewing similar to the second part of the MRCPsych Part I clinical examination is probably ideal. A faulty technique generally shows up within a 10-minute period and enables the supervisor to focus on a specific difficulty. To comment on an hour-long interview is much harder and can lead to a loss of focus.

Community visits to patients' homes, hostels, nursing homes, day centres and even police stations and prisons provide excellent opportunities for the trainee to see the consultant at work. These are especially valuable when the patient is a new referral, or when a marked change in circumstances has occurred. These are situations in which the educational supervisor's skills can be most closely observed, both in terms of the doctor-patient relationship, and ability to elicit and analyse the important clinical and social features of the case.

Given the pressures under which consultants currently work, providing such training is not always easy. The temptation is to go in the opposite direction, with a division of labour which often keeps the consultant and the trainee apart.

\section{Terms used in training}

Important terms in current use are supervision, appraisal and assessment.

\section{Supervision}

The apprenticeship model assumes learning is through modelling and by example. Supervision is also a major component. Here the educational supervisor is monitoring the trainee's work rather than vice versa. Apart from history-taking, interview skills and case management, the educational supervisor needs to monitor the trainee's note-keeping, patient's medicine cards, reports, case summaries and letters. For more senior trainees draft court reports, draft reports to hospital managers and tribunals, and the assessment of patients who have been referred for specialist services are also included.

It is important to stress that the educational supervisor has that title because he/she has taken on these supervisory responsibilities. Some supervisory support may be given to the trainee from the specialist registrar or the local College tutor, but it remains the educational supervisor's duty to take primary responsibility for this part of the teaching.
It will also be clear from the above that an educational supervisor who is part-time would find it difficult, if not impossible, to provide all the required supervision for a full-time trainee. An additional supervisor would generally be needed. If there are two supervisors, then one should be given the title 'Principal Educational Supervisor', that is the supervisor who undertakes the weekly one-to-one session.

One educational supervisor would also be hardpressed to manage two basic trainees and one specialist registrar. Furthermore, if the apprenticeship model is operating properly, then no trainee should have more than two educational supervisors.

Supervision is also required for psychotherapy. These supervisors are not usually educational supervisors in the strict sense unless the trainee is actually working for them. There is, nevertheless, a requirement that all trainees should receive psychotherapy supervision which is accessible in whatever location they rotate to during the course of their training. Traditional psychotherapy supervision may be individual or in groups but need not include the patient. Cognitive and behavioural supervision tends to be briefer, and concentrated in certain locations where the supervisor can see both the trainee and the patient. The same goes for family therapy.

Supervision of research is especially important, although not a mandatory part of MRCPsych training. Such supervision can only be carried out satisfactorily by teachers with a great deal of highquality research experience. Hence, most schemes have a designated research tutor.

\section{Appraisal and assessment}

It is generally agreed that appraisal refers to an individual's performance and is essentially confidential. It relates to that trainee's achievement of educational and job-related skills.

Assessment involves measurement of some of those skills against set goals and standards. This includes the completion of a set curriculum of activities and the passing of certain tests and examinations. The current debate about formative and summative assessment roughly corresponds with these two types of achievement. Hence the introduction of $\log$ books to enable trainees to keep track of their progress.

Negotiation of 'individual training agreements' (ITAs) as part of the educational contract required by regional postgraduate deans will make a big difference to formative assessment. Henceforth, any training post should include a mission statement and a set of educational and experiential 
goals which define how the trainee's professional expertise will be advanced during that period of attachment. This will be more specific than anything envisaged hitherto.

\section{Protected time}

Not least among the new educational goals which have been set is the requirement for the principal educational supervisor to provide one hour of oneto-one supervision per week for each trainee. (This is one of the reasons why one basic trainee and a specialist registrar is probably the optimum limit of what a principal educational supervisor should manage.)

Box 1 sets out the agenda for the weekly hour of one-to-one supervision.

Several surveys canvassing the views of registrars (Herriot et al, 1994), senior registrars (Bools \& Cottrell, 1990; Kingsbury \& Allsop, 1994), or both (Azuonye, 1997) have been carried out, highlighting many trainees' dissatisfaction with their current quality of supervision. Guidelines on how to conduct supervision sessions for psychiatric trainees are sparse, although other health professionals such as social workers have set out lists of desirable qualities. These include empathy, understanding and unconditional positive regard - qualities similar to those identified for nondirective counselling (Rogers, 1957; cited in Hawkins \& Shohet, 1989). Others have emphasised the need for the trainee to feel safe to express feelings of anxiety, fear or anger (Proctor, 1988, cited in Hawkins \& Shohet, 1989). Unfortunately, the latter may be desirable but is not always attainable, since the trainee is delivering services on behalf of a consultant who carries ultimate clinical responsibility. Furthermore, the consultant may be asked to provide a reference for the trainee. Hence, a readily accessible, confidential and independent counselling service must also be in place.

There is general agreement that the relationship between the trainee and educational supervisor is crucial. This relationship is most clearly exposed during one-to-one sessions: much of the relationship is governed by attitude. The wise educational supervisor perceives their trainee as a professional colleague who will soon become a fellow senior colleague. The relationship that is laid down at the outset can have far-reaching professional consequences for both of them. Trainees are acutely aware that their supervisor can 'make or break' them. They may be less aware of their own power to make or break the supervisor. It is therefore important to recognise that the relationship
Box 1. Agenda for weekly hour of one-toone supervision

\section{Education}

Wide-ranging discussions around current knowledge and good practice

Feedback on the trainee's development of general techniques such as historytaking, interview skills, note-keeping, case presentations and case management

Feedback by the trainees regarding their progress in specific techniques such as electroconvulsive therapy, psychological treatments, research methodology and audit

\section{Interpersonal skills}

Discussion ranging across all professional interactions with patients, relatives and staff, including self-presentation, attitude and issues of discrimination

\section{Managerial skills}

Helping the trainee to gain early experience through participation in local activities, including administration

\section{Personal development}

An overview of the trainee's current strengths and weaknesses. Their plans for professional development. Pacing themselves during the training period in terms of exams, sub-speciality experience, research, courses and conferences

\section{Pastoral}

Day-to-day problems probably related to local conditions of service and other relevant personal and domestic arrangements. This may include the trainee's time-management, multi-disciplinary team issues and the management of difficult patients

between these two professional colleagues should not be defined in terms more appropriate to therapy. Indeed, a good supervisor should be prudent enough to deflect certain kinds of sensitive material, referring it on to the independent counselling service. Both parties should remain aware of the other's potentially helpful contributions to the professional relationship and build 
on perceived strengths. In summary, the attitude on both sides needs to be based on a high level of mutual professional respect, the agenda must concentrate on personal and professional development and the form must not be confused with therapy.

An example (given by Fineman in 1985; cited in Hawkins \& Shohet, 1989), referring to a social worker with 'report work' difficulties, neatly illustrates this point:

I have regular meetings with my Supervisor but always steer clear of my problems coping with my report work. Can I trust her? I need her backing for my career progress, but will she use this as evidence against me?

A good supervisor will have discussed this topic as a matter of routine. It is part of their job to monitor the trainee's case notes, other documentation and summaries. Any trainee will encounter difficulty with these issues to some extent, and it does not require supervision in a quasi-therapeutic mode to deal with it. Should serious difficulties present themselves, such as poor self-confidence or obsessionality, then tactful advice may be needed. If that fails, then independent assistance must be sought.

Education is clearly central to the supervision process, but it has to be delivered in a supportive ambience. The position of a trainee presupposes lack of experience, uncertainty, insecurity, lack of confidence and fragile morale. Criticism is essential, but has to be delivered in such a way that it does not threaten the trainee's self-esteem. The usual way of achieving this is to approach it as a shared experience. For example, the apprehension a consultant feels when called to an emergency is much the same as that experienced by the trainee. It is the common fear of the unknown.

It is hard to know what to do about the occasional supervisor who seems driven to score intellectual points off the trainee in the name of education. Repeatedly asking questions to expose a trainee's ignorance may be a valid approach but can be overdone. A vigilant tutor may pick this up in local teaching sessions when other educational supervisors are present. They should be able to steer a consultant colleague towards a less intimidating style.

The opposite side of this coin is approval. It is hard to exaggerate the importance of acknowledging a job well done. It is easy to think that success is self-evident and that the good trainee is self-reinforcing, driven by some inner zeal. In fact, the contrary is true. Only the indifferent trainee is undeterred by having their efforts taken for granted.

A supportive ambience is especially important in psychiatry because of the constant close contact

\author{
Box 2. The consultants' view \\ Positive points \\ Stimulation by the trainee \\ Keeping up to date \\ Questioning \\ Companionship \\ Nurturing \\ Negative points \\ Shortage of time \\ Negative feedback \\ Coping with difficult trainees \\ Feeling threatened \\ Uncertainties about boundaries
}

with disturbed individuals. In this sense it is impossible to regard the supervisor and the trainee in isolation. The entire clinical team from top to bottom should be mutually supportive, with loyalty rewarded and reciprocated at all levels.

Most supervisors have mixed personal feelings about the weekly sessions of supervision. Boxes 2 and 3 set out some positive and negative points that have been raised by consultants and trainees over recent years.

Box 3. Examples of good and bad practice

Bad practice

Avoidance strategies and intellectualisation

No plan or agenda to hand

Using it as an extension of the ward round to discuss service matters rather than teaching

Good practice

A mutually trusting relationship with a plan and a sense of purpose established at the outset

Supervisor well-briefed about the trainee's current service and educational activities, especially in relation to the examination

A good working knowledge of the trainee's past experience to enable the supervisor to pitch his teaching in the right area and at the right level

Discussion to be trainee-led; supervisors should encourage trainees to bring their own agenda 
Box 4. Role of the College Tutor

Induction courses

In-house academic programme - topic teaching; guest speakers; journal clubs/ critical appraisal

Techniques - resuscitation; breakaway; ECT; interview techniques with video; exam-orientated workshops
The question arises as to what aspect of the trainee's education lies within the domain of the College tutor. Clearly this will vary from one locality to another, but Box 4 lists the educational activities for which the College tutor would normally be responsible.

\section{Future developments}

In the wake of the Calman recommendations, supervisors may need to seek out training in appraisal techniques and formative assessment. They may also be involved in drawing-up ITAs which set out the agenda of learning experiences which they undertake to deliver during the trainee's six-month clinical attachment. This is the training experience that regional postgraduate deans are purchasing with their $50 \%$ funding. A useful way for a trainee to review their educational progress in discussion with the supervisor is to complete the personal training log book. (Details of this can be obtained from the Postgraduate Educational Services Department of the College.) The local postgraduate dean may also require an additional written assessment for each trainee called the Record of Individual Training Agreement (RITA) which must be completed by the educational supervisor. Continuing Professional Development (CPD) requirements for educational supervisors are likely to develop quickly (Box 5). At present, this is mandatory only for College tutors.

In future it will be increasingly difficult for consultants to give the time that is required for
Box 5. Summary of future developments

Involvement in formative and summative assessment

Drawing up Individual Training Agreements

Assisting with trainees' log books

Sufficient CPD points to qualify as an educational supervisor their own educational needs as well as those of their trainees, without an equivalent reduction in their clinical workload. This will inevitably lead to a further expansion of the consultant workforce. Expansion in the numbers of non-consultant career-grade psychiatrists does not provide an answer because they too have educational needs. Increased levels of aspiration in education will therefore come with a substantial price tag, and cannot be absorbed as a cost-free part of the service.

\section{Acknowledgement}

The authors are indebted to the Dean of the Royal College of Psychiatrists, Professor John Cox, for his guidance and helpful comments in the preparation of this paper.

\section{References}

Azuonye, I. O. (1997) Educational supervision sessions between consultants and trainees. Psychiatric Bulletin, 21, 154-155.

Bools, C. \& Cottrell, D. (1990) Future child and adolescent psychiatrists: a further survey of senior registrar training. Psychiatric Bulletin, 14, 611-615.

Buckley, E. G. (1995) Apprentices or spinning tops? Rotational training programmes in postgraduate medical education. Medical Education, 29, 391-392.

Hawkins, P. \& Shohet, R. (1989) Supervision in the Helping Professions. Milton Keynes: Open University Press.

Herriot, P., Bhui, K. \& Lelliott, P. (1994) Supervision of trainees. Psychiatric Bulletin, 18, 474-476.

Kingsbury, S. \& Allsop, M. (1994) Direct consultant supervision of higher trainees in child and adolescent psychiatry. A survey of expectation and practice. Psychiatric Bulletin, 18, 225-229. 